\title{
Integrated Flight/Propulsion Control Design for a STOVL Aircraft Using H-Infinity Control Design Techiques
}

Sanjay Garg and Peter J. Ouzts

Lewis Research Center

Cleveland, Ohio

Prepared for the

American Control Conference sponsored by the American Automatic Control Council Boston, Massachusettes, June 26-28, 1991

(NASA-TM-104340) INTFGDATED

FLIGHT/PRCPULSION CONTROL DESIGN FOR A STOVL

AIRCRAFT USING H-INFINITY CONTROL DESTGN

IECHNILUES (NASA) $33 \mathrm{p}$
CSCL $21 \mathrm{~F}$
$N 91-21140$

Unclas

0009041

\section{N/SN}




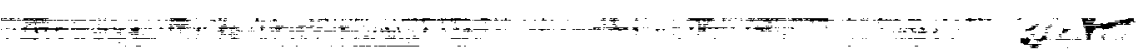




\title{
INTEGRATED FLIGHT/PROPULSION CONTROL DESIGN FOR A STOVL
}

\section{AIRCRAFT USING H-INFINITY CONTROL DESIGN TECHNIQUES}

\author{
Sanjay Garg 1 and Peter J. Ouzts ${ }^{2}$ \\ NASA Lewis Research Center \\ Advanced Control Technology Branch \\ Cleveland, OH 44135
}

\begin{abstract}
Results are presented from an application of $H_{\infty}$ control design methodology to a centralized integrated flight/propulsion control (IFPC) system design for a supersonic Short Take-Off and Vertical Landing (STOVL) fighter aircraft in transition flight. The emphasis is on formulating the $\mathrm{H}_{\omega}$ control design problem such that the resulting controller provides robustness to modelling uncertainties and model parameter variations with flight condition. Experience gained from a preliminary $H_{\omega}$ based IFPC design study performed earlier is used as the basis to formulate the robust $\mathrm{H}_{\omega}$ control design problem and improve upon the previous design. Detailed evaluation results are presented for a reduced order controller obtained from the improved $H_{\infty}$ control design showing that the control design meets the specified nominal performance objectives as well as provides stability robustness for variations in plant system dynamics with changes in aircraft trim speed within the transition flight envelope. A controller scheduling technique which accounts for changes in plant control effectiveness with variation in trim conditions is developed and off-design model performance results are presented with the scheduled controller.
\end{abstract}

1Aerospace Engineer, Senior Member AIAA

${ }^{2}$ Aerospace Engineer 


\section{Introduction}

The trend in future military fighter/tactical aircraft design is towards aircraft with new/enhanced maneuver capabilities such as Short Take-Off and Vertical Landing (STOVL) and high angle of attack performance. An integrated flight/propulsion control (IFPC) system is required in order to obtain these enhanced capabilities with reasonable pilot workload. An integrated approach to control design is then necessary to achieve an effective IFPC system. Such a design approach is currently being developed at NASA Lewis Research Center under an in-house research effort. This methodology is referred to as IMPAC - Integrated Methodology for Propulsion and Airframe Control [1]. The significant features of the IMPAC methodology are that it consists of first designing a centralized controller considering the airframe and propulsion systems as one integrated system and then partitioning the centralized controller into decentralized subsystem controllers for state-of-the-art IFPC implementation.

The major issue related to the centralized controller design portion of IMPAC is the choice of the control synthesis technique that "best" suits the IFPC objectives. Not only should the synthesis technique provide for means of formulating the design criteria for the centralized control design such that it adequately reflects the performance specifications of the "total" system, i.e., the airframe integrated with the propulsion system, but it should also result in controllers of reasonable complexity with guaranteed performance and robustness characteristics. Recent advances in $\mathrm{H}_{\infty}$ control theory [2,3] and computational algorithms to solve for $\mathrm{H}_{\infty}$ optimal control laws [4] have made this theory a viable candidate to be applied to complex multivariable control design problems. A preliminary investigation of the applicability of $\mathrm{H}_{\infty}$ control theory to the centralized feedback controller design portion of the IMPAC approach was conducted earlier via an example IFPC design study [5]. The results reported in Ref. [5] are quite encouraging in that they demonstrate that $\mathrm{H}_{\infty}$ control theory has the promise to provide the framework to meet the requirements of a centralized IFPC design. However, the control design of Ref. [5] was a preliminary 
design and detailed evaluation of that design identified various areas in which the controller performance needed to be improved. The objectives of this paper are to develop insight into formulating a robust control problem within the $\mathrm{H}_{\infty}$ control design framework and to improve upon the control design of Ref. [5]. Towards this goal results are presented from a $\mathrm{H}_{\mathrm{w}}$ based IFPC redesign for the linear model of a STOVL aircraft in transition flight considered earlier in Ref. [5]. Also presented in this paper are the closed-loop performance evaluation results for off-design plant models using controller scheduling based on a scheme that exploits the robustness properties of the $\mathrm{H}_{\infty}$ controller that are built into the nominal control design by appropriate problem formulation.

The paper is organized as follows. The vehicle models to be used for control design and evaluation are first discussed. The $H_{\infty}$ control design is then presented along with some discussion of the formulation of the IFPC design objectives within the framework of the $\mathrm{H}_{\mathbf{D}}$ control problem. The emphasis is on formulating the problem such that the resulting controller is robust to modelling uncertainties and parameter variations with changes in flight condition. Evaluation results are presented for a reduced order approximation of the improved $\mathrm{H}_{\omega}$ controller and improvements over the controller design of Ref. [5] are demonstrated. A "simple" controller scheduling scheme that accounts for changes in plant control effectiveness for varying trim conditions is then discussed and evaluation results are presented for off-design models.

\section{Vehicle Model}

The vehicle considered in this study is representative of the delta winged E-7D supersonic STOVL airframe powered by a high bypass turbofan engine [6]. The aircraft is equipped with the following controls: ejectors to provide propulsive lift at low speeds and hover; a $2 \mathrm{D}-\mathrm{CD}$ vectoring aft nozzle with afterburner for supersonic flight; a vectoring ventral nozzle for pitch control and lift augmentation during transition; and jet reaction control systems (RCS) for pitch, roll and yaw control during transition and hover. A schematic diagram of the aircraft with relative location of the various control effectors 
mentioned above is shown in Fig. 1. Engine compressor bleed flow is used for the RCS thrusters and the mixed engine flow is used as the primary ejector flow. Detailed ducting diagrams of the engine and discussion of the ejector STOVL concept are available in Ref. [6].

Currently, two separate computer simulations, one for the airframe and one for the propulsion system, are being used to assess performance capabilities of the aircraft and to generate open-loop linear models for control design [6]. The procedure for generating integrated airframe and propulsion models for control design and evaluation from the two separate simulations is discussed in Ref. [5]. The integrated linear design model used in this study is of the form

$$
\dot{\bar{x}}=A \bar{x}+B \bar{u} ; \bar{y}=C \bar{x}+D \bar{u}
$$

where the state vector is

$$
\overline{\mathbf{x}}=[\mathrm{u}, \mathrm{v}, \mathrm{w}, \mathrm{p}, \mathrm{q}, \mathrm{r}, \phi, \theta, \mathrm{N} 2, \mathrm{~N} 25, \mathrm{~T} 41, \mathrm{~T} 3, \mathrm{P} 6]^{\mathrm{T}}
$$

with

$$
\begin{aligned}
& \mathrm{u}=\text { Axial Velocity, } \mathrm{ft} / \mathrm{s} \\
& \mathrm{v} \cdot=\text { Lateral Velocity, } \mathrm{ft} / \mathrm{s} \\
& \mathrm{w}=\text { Vertical Velocity, } \mathrm{ft} / \mathrm{s} \\
& \mathrm{p} \quad=\text { Roll Rate, } \mathrm{rad} / \mathrm{s} \\
& \mathrm{q}=\text { Pitch Rate, } \mathrm{rad} / \mathrm{s} \\
& \text { r = Yaw Rate, rad } / \mathrm{s} \\
& \phi \quad=\text { Roll Attitude, rad } \\
& \theta \quad=\text { Pitch Attitude, rad } \\
& \text { N2 = Engine Fan Speed, rpm } \\
& \text { N25 = High Pressure Compressor Speed, rpm } \\
& \mathrm{T} 41=\text { High Pressure Turbine Inlet Temp., }{ }^{\circ} \mathrm{R} \\
& \text { T3 = Combustor Inlet Temp., }{ }^{\circ} \mathrm{R} \\
& \text { P6 = Tailpipe Entrance Total Pressure, psi, }
\end{aligned}
$$

the control inputs are

$$
\overline{\mathrm{u}}=[\delta, \delta \mathrm{a}, \delta \mathrm{r}, \mathrm{AQR}, \mathrm{AYR}, \mathrm{ARR}, \mathrm{WF}, \mathrm{A} 8, \mathrm{ETA}, \mathrm{A} 78, \mathrm{ANG} 8, \mathrm{ANG} 79]^{\mathrm{T}}
$$

with

$$
\begin{array}{ll}
\delta \mathrm{e} & =\text { Elevator Deflection, deg } \\
\delta \mathrm{a} & =\text { Aileron Deflection, deg } \\
\delta \mathrm{r} & =\text { Rudder Deflection, deg }
\end{array}
$$




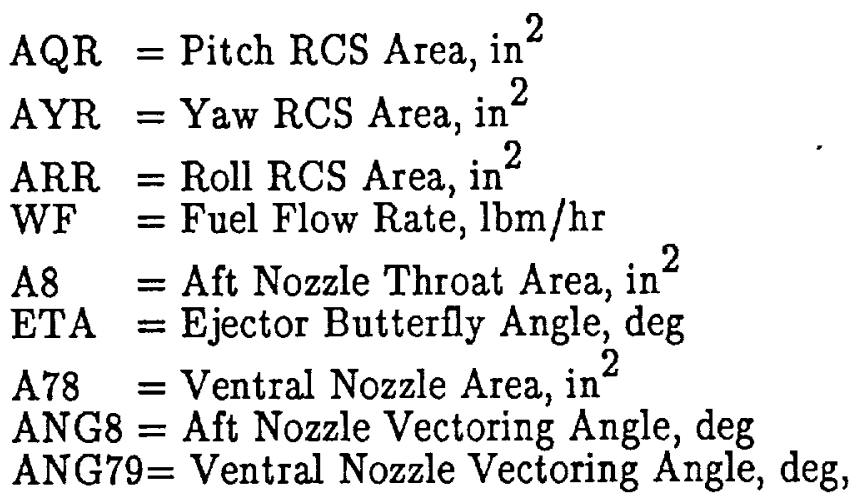

and the outputs are

$$
\overline{\mathrm{y}}=[\mathrm{V}, \mathrm{V}, \theta, \mathrm{q}, \gamma, \phi, \mathrm{p}, \beta, \mathrm{r}, \mathrm{N} 2, \hat{\beta}]^{\mathrm{T}}
$$

with

$$
\begin{array}{ll}
\mathrm{V} & =\text { True Airspeed, } \mathrm{ft} / \mathrm{s} \\
\mathrm{V} & =\text { Total Acceleration, } \mathrm{ft} / \mathrm{s}^{2} \\
\gamma & =\text { Longitudinal Flight Path Angle, deg } \\
\beta & =\text { Sideslip Angle, deg } \\
\beta & =\text { Rate of change of Sideslip Angle, deg/s. }
\end{array}
$$

The other outputs are as discussed under state description except that the angular positions and rates are in degrees.

Some discussion of the choice of control inputs $\bar{u}$ for the linear design model is relevant here. The choice of outputs $\bar{y}$ is discussed later in the paper. The $E-7 D$ aircraft is equipped with left and right elevons on the trailing edge of the delta wing. Collective deflection of the elevons provides the classical elevator pitch control while differential use of the elevons provides the aileron roll control. So the elevator $(\delta \mathrm{e})$ and aileron ( $\delta \mathrm{a})$ along with the rudder $(\delta \mathrm{r})$ are used as the airframe control inputs in the design model. Only 3 RCS areas, AQR, AYR and ARR, are used as RCS control inputs in the linear design model whereas the full nonlinear model has 5 controlled RCS areas. The reasons for this are that the nose pitch RCS and the two yaw RCS thrusters provide thrust in only one direction as shown in Fig. 1, and the wing tip roll RCS thrusters are to be used differentially for roll control and collectively for pitch control. For instance yaw RCS thrusters provide only forward thrust, so left yaw RCS is used for right yaw and right yaw 
RCS is used for left yaw in the nonlinear model. Using both left and right yaw RCS areas as control inputs in the design model can result in a control design that uses the two areas differentially to enhance yaw control which is inconsistent with the actual implementation. Similar reasons apply for pitch and roll RCS area selections. An RCS distribution logic that will distribute the three design model RCS commanded areas to the five actual areas in the nonlinear control implementation is shown in Fig. 2. Since the nose pitch RCS thruster only provides positive (pitch up) pitching moment, a negative AQR command is distributed among the left and right wing tip RCS thrusters to generate the commanded negative pitching moment taking into account the relative pitch control effectiveness of the nose and wing tip RCS thrusters.

Fig. 2 is presented here to clarify the discussion on choice of RCS areas for linear design model although the logic of Fig. 2 is not used to evaluate the control designs presented in this paper. Note that there is an absolute nonlinearity in the relationship from commanded RCS areas to compressor bleed flow demand in that although the RCS area may be positive or negative depending on the desired direction of RCS thrust, the compressor bleed flow demand (WB3) to generate the thrust is always positive. For a linear model trimmed about zero RCS areas, this relationship is of the form WB3 $i=\mathrm{K}_{i}|\mathrm{~A} i \mathrm{R}|$ where WB3 $i$ is the demanded bleed flow due to AiR command with $i$ representing $\mathrm{Q}, \mathrm{Y}$ or $\mathrm{R}$ for pitch, yaw or roll RCS, respectively, $\mathrm{K}_{i}$ is an appropriate constant and $|\cdot|$ represents absolute value. This nonlinearity was not taken into account in the linear control design of Ref. [5] and the resulting controller was shown to lead to unacceptable performance when evaluated with this nonlinearity. In this paper, the critical absolute nonlinearity from RCS area commands to WB3 demand is accounted for in the linear control design process by a proper formulation of the control design problem within the $H_{\infty}$ framework. The details of this formulation are discussed later in the paper.

The control inputs, WF, A8, ETA, A78, ANG8 and ANG79 in the vector $\bar{u}$, are the propulsion system inputs. The ejector butterfly valve angle (ETA) controls the engine 
airflow to the ejectors, thus providing a means of controlling ejector thrust. There are separate control valves for the left and right ejectors, however the two valve angles are set to be equal in the aircraft simulation because no test data is available on the differential use of the ejectors for roll control. Therefore only one butterfly valve angle is used as the control input in the design model. The other five propulsion system control inputs in the design model were just as defined in the full cycle-deck engine simulation [6].

The flight phase considered in this study is the decelerating transition during approach to hover landing. This phase presents a challenging control design problem because the control of the aircraft is transitioning from aerodynamically generated forces and moments to those generated by the propulsion system. For this study, three linear integrated models were obtained corresponding to steady-state level flight at trim speeds of $\mathrm{V}_{\mathrm{o}}=60,80$ and 100 Knots with trim flight path angle $\gamma_{\mathrm{O}}=-3 \mathrm{deg}$ for all three models. The trim strategy used to generate the linear models is as follows : i) The aircraft pitch attitude was set at $\theta_{0}=7 \mathrm{deg}$ to provide adequate visibility during landing, and the elevon settings were chosen to correspond to elevator deflection $\delta e_{0}=20$ deg so that adequate elevator control authority is available for maneuvers during transition; ii) The aft nozzle vectoring angle was set to $A N G 8_{0}=0$ so that the total vectoring authority is available for pitch control, and the ventral nozzle vectoring angle was set to $A N G 79_{0}=64$ deg to ensure that the aircraft can be trimmed at the low speed ( $60 \mathrm{Knots}$ ) with small but nonzero aft nozzle thrust, hence nonzero throat area. This trim strategy leaves adequate A8 and ANG79 control authority available for these controls to be used for active speed and pitch control in transition; iii) The aircraft is then trimmed by using the three thrusts - aft nozzle, ventral nozzle and the combined ejectors, as the trim controls. The resulting trim values of A8, ETA, and A78 for the three trim speeds are listed in Table 1. Also listed in Table 1 are the trim values of fuel flow (WF) and engine fan speed (N2) which define the engine operating point. Note that the quantities shown in Table 1 are a percentage of the corresponding trim values for the $80 \mathrm{Knot}$ model. As seen from Table 1 , thrust is 
transferred from aft nozzle to ventral nozzle as the aircraft slows down and the engine operating point is moved up to a higher gross thrust level (increased WF and N2) to generate the propulsive lift needed to compensate for the loss in aerodynamic lift.

Open loop frequency-domain and time-domain analyses of the three linear models indicated that the $80 \mathrm{Knot}$ model provides a "good average" of the three models in terms of input/output response behavior. Thus the $80 \mathrm{Knot}$ model was used for control design with the $60 \mathrm{Knot}$ and $100 \mathrm{Knot}$ models being used to evaluate the stability and performance robustness of the nominal design, develop controller scheduling and evaluate off-design performance. The eigenvalues of the linear models for the three flight conditions are listed in Table 2 and the airframe modes are identified in terms of their "classical" interpretation [7]. As seen from Table 2, the aircraft is unstable in pitch with the short period (SP) mode becoming less unstable as the trim speed decreases. Also the dutch roll mode damping is very low and it decreases with trim speed with the mode going unstable at 60 Knots. The engine temperature and pressure modes are very fast compared to the engine rotor dynamics and aircraft modes. Ideally these fast modes will not be considered in the linear design model in order to reduce the complications in the control synthesis procedure. However, the approach taken in this study is to include these modes in the design model and reduce the complexity of the controller through order-reduction after initial controller synthesis.

\section{H $_{\mathbf{w}}$ Control Design}

\section{Design Methodology}

The IFPC design problem discussed earlier was formulated as a command tracking, disturbance rejection problem within the framework of the general mixed sensitivity $H_{\omega}$ control problem [8]. The detailed block diagram for the $\mathrm{H}_{\infty}$ formulation of the IFPC feedback control design is shown in Fig. 3. The three transfer functions that are of interest for such a problem are the sensitivity function $S(s)$, the complementary sensitivity function $\mathrm{T}(\mathrm{s})$, and the control transmission function $\mathrm{C}(\mathrm{s})$. These represent the closed-loop transfers 
from the reference commands and disturbances to tracking errors, controlled variables and commanded control inputs, respectively. In order to influence both the low-frequency and high-frequency properties of the closed-loop system it is desirable to find a controller $\mathrm{K}(\mathrm{s})$ which minimizes a weighted norm of a combination of these three transfer functions, i.e.

$$
\min \|H(j \omega)\|_{\infty} \text { with } H(j \omega)=\left[\begin{array}{l}
W_{S}(j \omega) \cdot S(j \omega) \\
W_{T}^{(j \omega)} \cdot T(j \omega) \\
W_{C}(j \omega) \cdot C(j \omega)
\end{array}\right]
$$

Note that $\|H(j \omega)\|_{\infty}$ is the highest value over all frequencies $\omega$ of the maximum singular value of $H(j \omega)$, i.e.

$$
\| \mathrm{H}\left(\mathrm{j} \omega \|_{\infty}=\max _{\omega}(\bar{\sigma}[\mathrm{H}(\mathrm{j} \omega)])\right.
$$

The weighting functions $\mathrm{W}_{\mathrm{S}}, \mathrm{W}_{\mathrm{T}}$, and $\mathrm{W}_{\mathrm{C}}(\mathrm{j} \omega)$ are the "knobs" used by the control designer to "tune" the controller $\mathrm{K}(\mathrm{s})$ such that the design objectives are met. For instance choosing $\mathrm{W}_{\mathrm{S}}$ to be large at low frequency ensures good command tracking performance and choosing $\mathrm{W}_{\mathrm{T}}$ to be large at high frequencies ensures robustness to high frequency unmodelled dynamics. $W_{C}$ are chosen to ensure that control actuation bandwidths and control rate and deflections are practically achievable.

The $\mathrm{H}_{\mathrm{w}}$ tracking formulation of Fig. 3 allows for feedback of plant measurements other than just tracking errors as inputs to the controller. This formulation then allows the simultaneous design of inner loop plant augmentation (stability or response shaping) and command tracking system. Such plant augmentation is an integral part of flight control design since the overall objective is to design a system for desired piloted handling qualities and not just an automatic command tracking system. Also, it has been shown in Ref. [9] that if a tracking problem is formulated within the $H_{\infty}$ framework as purely a servo-mechanism problem, i.e. with controller inputs being just the tracking errors, then the $H_{\infty}$ controller will be such that its transmission zeros cancel the stable poles of the design plant thus resulting in a closed-loop system that will have almost no robustness to plant modeling uncertainties. Allowing for feedback augmentation within the $\mathrm{H}_{\omega}$ control 
formulation overcomes this problem of lack of robustness as demonstrated in Ref. [5].

\section{Design Specifications}

The vectors $\overline{\mathrm{u}}$ and $\overline{\mathrm{y}}$ in Fig. 3 are the integrated design model inputs and outputs, respectively, as discussed in the previous section. The controlled variables $\bar{z}$ were selected to be

$$
\bar{z}=[\mathrm{Vv}, \mathrm{Qv}, \gamma, \mathrm{Pv}, \beta, \mathrm{N} 2]^{\mathrm{T}}
$$

with $\mathrm{Vv}=\mathrm{V}+0.1 \mathrm{~V}, \mathrm{Qv}=\mathrm{q}+0.3 \theta, \mathrm{Pv}=\mathrm{p}+0.1 \phi$ and the others as discussed under plant outputs. This blending of controlled variables was chosen to provide the response types that are desirable for good handling qualities $[10,11]$ in transition flight. The choice of $\mathrm{Vv}$ corresponds to designing an acceleration (deceleration) command system with velocity hold, and the choice of $\mathrm{Qv}$ and $\mathrm{Pv}$ correspond to designing a rate command-attitude hold system. The break frequencies for switching from rate to attitude command for the case of $\mathrm{Qv}$ and $\mathrm{Pv}$, and from acceleration to velocity command for the case of $\mathrm{Vv}$, were chosen based on open-loop control effectiveness studies. For instance, the elevator $(\delta e)$ is effective in pitch rate control in the frequency range of $0.3 \mathrm{rads} / \mathrm{s}$ to $10 \mathrm{rads} / \mathrm{s}$ and is effective in pitch attitude $(\theta)$ control for frequencies below 0.3 rads/s. The choice of $\gamma$ in $\bar{z}$ provides for flight path angle control and the choice of N2 provides for tracking the fan speed commands generated by the engine operating schedule logic.

Designing the feedback controller $\mathrm{K}(\mathrm{s})$ to provide decoupled command tracking of the individual elements of $\bar{z}$ will result in a system that provides independent control of acceleration, pitch, flight path angle, roll and sideslip from the various pilot control effectors such as stick, throttle and rudder pedals etc., thus reducing pilot workload, and also control of the propulsion system operating point (N2) independent of the aircraft motion. Independent control of roll (Pv) and sideslip angle $(\beta)$ will result in a control system that provides automatic turn coordination thus further reducing pilot workload.

The choice of outputs $\overline{\mathrm{y}}$, in (4), is consistent with the various quantities used for feedback in classical aircraft control augmentation [7]. Rate feedback provides for improved 
damping while position (angles) feedback improves natural frequency of the appropriate mode.

Based on the experience gained from the control design study of Ref. [5], an important criterion for control design is that the closed-loop system be robust to the absolute nonlinearity associated with the bleed flow demand from the RCS area commands see earlier discussion. Also, the control design of Ref. [5] was such that it did not further stabilize the dutch roll mode, i.e. the open-loop dutch roll mode was also a mode of the closed-loop system with the designed controller. This resulted in an unstable closed-loop system for the off-design integrated model at 60 Knots due to the dutch roll mode being unstable at that flight condition. For this redesign effort, stabilization of the dutch roll mode to guarantee stable closed loop system over the transition flight conditions being considered was included as a design specification.

\section{Control Design}

The design plant inputs and controlled outputs were normalized by maximum allowable deflections $\left(\overline{\mathrm{u}}_{\max }\right)$ and maximum commanded values to be tracked $\left(\overline{\mathrm{z}}_{\mathrm{c}_{\max }}\right)$ respectively. The $\bar{u}_{\max }$ were chosen to be reasonable deviations from the nominal (trim) values such that the total control deflection limits (as incorporated in the actuator models in the nonlinear model) will not be exceeded. Some of the $\bar{u}_{\max }$ values corresponding to the propulsion system controls were further reduced to ensure that the total control usage will be within the limits imposed by safety requirements. For example, the allowable engine fuel flow for a given operating point is limited by the engine acceleration/deceleration schedule. The $\bar{z}_{c_{\max }}$ were chosen based on handling qualities control requirements and open-loop control effectiveness analysis of the design plant to ensure that each element of $\bar{z}$ can be commanded individually to its maximum value within its frequency range of interest without exceeding $\bar{u}_{\max }$ value for any of the control inputs. The singular values of the scaled design plant for the 6 controlled variables defined in eqn. (5) are shown in Fig. 4. The fact that the minimum singular value in Fig. 6 is less than 1 implies that there exist 
combinations of numerical values of commands $\bar{z}_{c}$ such that although each element of $\bar{z}_{c}$ is less than its maximum value, the combined commands $\bar{z}_{c}$ cannot be tracked without exceeding the control limits $\overline{\mathrm{u}}_{\max }$ for some control input.

The sensitivity weights $\mathrm{W}_{\mathrm{S}}$ and the complementary sensitivity weights $\mathrm{W}_{\mathrm{T}}$ for each of the controlled variables were chosen to be first-order, to provide adequate frequency response shaping without overly increasing the resulting controller order. The $\mathrm{W}_{\mathrm{S}}$ zero and pole for each controlled variable were chosen to result in a low frequency gain of 1000 , gain crossover frequency of 3 to 4 times the control bandwidth desired for good handling qualities for the controlled variable of interest, and a high frequency gain of 0.1. Such a choice of $W_{S}$ reflects the desire to synthesize a sensitivity function which give good steady-state tracking performance in the presence of disturbances and low frequency modelling errors, good tracking performance up to the desired bandwidth of control and reduced emphasis on tracking at high frequencies where there are significant modelling errors and uncertainties. The $\mathrm{W}_{\mathrm{T}}$ were chosen to obtain a low frequency gain of 0 , gain crossover frequency of about 1.2 times the corresponding $\mathrm{W}_{\mathrm{S}}$ gain crossover frequency, and a high frequency gain of 100 . This choice of $\mathrm{W}_{\mathrm{T}}$ ensures that the plant outputs are not penalized at low frequencies where command tracking is to be emphasized while at high frequencies the plant outputs are penalized heavily to provide controller gain attenuation for robustness to unmodelled dynamics.

As part of the control weighting $\mathrm{W}_{\mathrm{C}}$, both the control inputs and control rates were weighted with $W_{u}$ in Fig. 3 chosen to be the inverse of $\bar{u}_{\max }$ and $W_{\dot{u}}$ chosen to be inverse of maximum control rate for each control input. Since using full order actuator models for each control input would have resulted in a very high-order controller, first order actuator approximations were used in the control design. Describing function analysis [12] of the full order actuators was first performed to determine the degradation in actuator bandwidth due to rate limiting when control commands corresponding to $\bar{u}_{\max }$ are used at all frequencies. The worst-case rate-limited actuator bandwidth was then used as the 
bandwidth for first-order design actuators. For example, the pitch RCS area actuator bandwidth is $20 \mathrm{rad} / \mathrm{s}$ but the rate limit is $3.0 \mathrm{in}^{2} / \mathrm{s}$ which results in a worst case bandwidth of $6.0 \mathrm{rad} / \mathrm{s}$ for $A Q R_{\text {max }}$ of $0.7 \mathrm{in}^{2}$. Using such an approximation for the actuators in the design guarantees performance robustness in the presence of actuator rate limiting.

The bleed flow demand from the RCS acts as a disturbance on the engine operating point. In the propulsion system simulation and the linear model generated from this simulation, bleed flow appears as an external disturbance. However, when the airframe and propulsion models are integrated there is no explicit dependence on bleed flow since the bleed flow is generated from the RCS area commands which are the inputs to the integrated model. As pointed out earlier, the linear design model does not account for the absolute nonlinearity from the RCS area commands to bleed flow demand, so the effect of the RCS areas on the engine states as it appears in the linear design model is erroneous. The linear design model was modified such that the elements of the B matrix from the RCS areas to engine states are zero, i.e. the RCS areas do not affect the engine operating point, and bleed flow was added as an external disturbance affecting the engine dynamics as in the linear engine model. For $\mathrm{H}_{\omega}$ control synthesis, the bleed flow disturbance was modelled as a zero-mean Gaussian white noise process with an intensity of $7 \mathrm{lbm} / \mathrm{s}$, which is the maximum possible RCS bleed flow, and was considered to be a measurement available for feedback. Although bleed flow is not measurable, it can be estimated as a function of RCS areas and ambient and bleed duct pressure conditions or the bleed flow feedback can be implemented as nonlinear feedback of the RCS area commands. Since the RCS is used for control of aircraft angular rates, the bleed flow disturbance was filtered by a first order filter with a bandwidth of $3.5 \mathrm{rads} / \mathrm{s}$ which is representative of desired angular rate control bandwidths.

A procedure for providing robustness to plant model variations within the framework of the $H_{w}$ control problem is to use internal noise models as disturbances which 
mimic the effects of model variations [13]. Such an approach was used in the current design study to provide enhanced lateral/directional stability by appropriate damping of the dutch roll mode and robustness to changes in the lateral/directional dynamics with decreasing trim airspeed. Side force, rolling moment and yawing moment changes were represented in the form of zero-mean white noise Gaussian disturbances in lateral acceleration $(\dot{v})$, roll acceleration $(\dot{p})$, and yaw acceleration $(\dot{r})$ with intensities of $0.5 \mathrm{ft} / \mathrm{s}^{2}$, $0.1 \mathrm{rad} / \mathrm{s}^{2}$, and $0.1 \mathrm{rad} / \mathrm{s}^{2}$ respectively. The overall $H_{\infty}$ control synthesis problem was then formulated as that of command tracking with bleed flow and lateral/directional disturbance rejection.

The design plant as discussed above is of $38 \mathrm{th}$ order consisting of the 13th order integrated airframe/propulsion system design model, first order actuators for the 12 control inputs, first order sensitivity and complementary sensitivity weights for the 6 controlled variables, and the first order filter for the bleed flow disturbance. So the $\mathrm{H}_{\infty}$ controller using the algorithm of Ref. [2] will be of $38 \mathrm{th}$ order. The $\mathrm{H}_{\infty}$ control design results with this design plant are shown in Fig. 5 in terms of the closed loop maximum singular values of the combined weighted functions $\bar{\sigma}[\mathrm{H}(\mathrm{j} \omega)]$, weighted errors $\bar{\sigma}\left[\mathrm{W}_{\mathrm{S}} \overline{\mathrm{e}}(\mathrm{j} \omega)\right]$, weighted controlled outputs $\bar{\sigma}\left[\mathrm{W}_{\mathrm{T}} \overline{\mathrm{z}}(\mathrm{j} \omega)\right]$, weighted controls $\bar{\sigma}\left[\mathrm{W}_{\mathrm{u}} \overline{\mathrm{u}}(\mathrm{j} \omega)\right]$, and weighted control rates $\bar{\sigma}\left[\mathrm{W}_{\dot{\mathrm{u}}} \dot{\overline{\mathrm{u}}}(\mathrm{j} \omega)\right]$ with the commands $\bar{z}_{c}$ as inputs. $\|H(j \omega)\|_{\infty}=10$ is achieved for this controller as seen from Fig. 5. In general a control design with $\|\mathrm{H}(\mathrm{j} \omega)\|_{\infty} \leq 1$ ensures that all the design specifications that are formulated through the various weightings will be met. However, this was not the case in the present design, because as stated earlier the minimum singular value of the scaled design plant itself was much less than 1 . The fact that control efforts greater than $\bar{u}_{\max }$ will be required to track some combinations of commands is evident from the large $(>1)$ maximum singular values of weighted controls at low frequencies. The fact that maximum singular value of weighted errors is greater than 1 at low frequencies indicates the performance/control trade-off made in the $\mathrm{H}_{\infty}$ minimization procedure. The 
fact that the maximum singular values of the weighted controlled outputs and control rates are less than 1 over all frequencies indicates that the $\mathrm{H}_{\infty}$ controller provides adequate "loop gain" roll-off for the closed-loop system to be robust to unmodelled high frequency dynamics and that the control rate limits will not be exceeded for any combinations of commanded variables. Further evaluation results are presented in the following section with reference to a reduced-order controller obtained from the $\mathrm{H}_{\infty}$ controller.

\section{Controller Reduction and Evaluation}

The controller order was reduced from 38 to 14 using a combination of modal residualization [14] and balanced realization [15] reduction techniques. The order was first reduced from 38 to 22 by modal residualization of the high frequency controller modes. The $22^{\text {nd }}$ order controller was reduced to $16^{\text {th }}$ order by a balanced realization approximation which was then reduced to $14^{\text {th }}$ order again by residualization of the high frequency modes. The eigenvalues of the final reduced order controller were bounded by $|\lambda|<10$ thus indicating that digital implementation of the controller can be achieved with reasonable sampling rates. The performance with the full order and reduced order controllers is compared in Fig. 6 in terms of the maximum and minimum singular values of the closed-loop tracking system, $\bar{\sigma}[T(j \omega)]$ and $\underline{\sigma}[\mathrm{T}(\mathrm{j} \omega)]$ with $\bar{z}(\mathrm{~s})=\mathrm{T}(\mathrm{s}) \overline{\mathrm{z}}_{\mathrm{c}}(\mathrm{s})$. Clearly, there is no significant loss in tracking performance with the reduced order controller. Note that other modern control reduction techniques such as frequency-weighted balanced realization [16] were not used because it was not clear how to apply these techniques for a controller structure which includes external disturbances as inputs (bleed flow in this particular case).

Extensive frequency-domain and time-domain analyses were performed to evaluate the closed-loop performance and robustness with the linear design model. All these analyses indicated that the reduced-order controller provides decoupled command tracking with desired tracking bandwidths and reasonable control actuation requirements. Note that although the open-loop design model is decoupled in the longitudinal and lateral/directional dynamics, coupling between these axes is introduced through the use of 
RCS control. For instance using the yaw RCS will result in change in velocity because the yaw RCS generates axial force. So the fact that the control design achieves decoupled response in longitudinal and lateral/directional axes while using RCS for active control is significant.

The performance of the control design in the presence of the absolute nonlinearity from commanded RCS areas to compressor bleed flow demand was evaluated by including these nonlinear effects in the linear $80 \mathrm{Knot}$ design model. An example result is shown in Fig. 7 in terms of the closed-loop pitch attitude and engine fan speed response to a pitch variable $(\mathrm{Qv})$ command. The $\mathrm{Qv}$ command was chosen to correspond to a transient pitch rate command and a steady-state pitch attitude command. Also shown in Fig. 7 is the corresponding closed-loop system response with the control design of Ref. [5]. The current design provides the desired improvement over the control design of Ref. [5] in that it maintains good pitch tracking and fan speed regulation performance in the presence of the absolute bleed flow nonlinearity. Thus the formulation of the $\mathrm{H}_{\infty}$ control problem to reject bleed flow disturbance with the modified design plant, the modification being the removal of the RCS area effect on the engine dynamics, was successful in providing performance robustness to the bleed flow absolute nonlinearity.

Another important design criterion discussed earlier was to provide stability robustness to changes in the lateral/directional dynamics specially with reference to the low damping of the dutch roll mode. For the current control design, the open-loop dutch roll mode was no longer a closed-loop mode with the 80 Knot design plant. Moreover, all the closed-loop modes were well damped with the smallest damping ratio being 0.4 . Detailed stability robustness evaluation of the control design to variations in the plant system A matrix due to changes in trim speed were conducted using structured singular value robustness tests [17]. The procedure for this stability robustness evaluation is discussed in the following.

First the variations in the airframe portion of the plant A matrix with changes in 
trim speed were identified. With the 80 Knot model $A$ matrix as the nominal, thirteen elements of the airframe portion of the A matrix showed a change of $25 \%$ or greater in going from 80 Knots to 60 Knots or 80 Knots to 100 Knots. These elements correspond to change in axial ( $\mathrm{X}$-axis) force due to pitch rate, side force ( $\mathrm{Y}$-axis) due to roll rate and yaw rate, vertical force ( $\mathrm{Z}$-axis) due to axial speed $(u)$, vertical speed $(w)$ and pitch rate, rolling moment due to roll rate and yaw rate, pitching moment due to axial speed and pitch rate, and yawing moment due to side velocity ( $v$ ), roll rate and yaw rate. Also the percentage change in the $A$ matrix elements was approximately symmetrical about the nominal A matrix. For a given trim speed, $V_{T}$, these thirteen elements of the $A$ matrix were then modelled using the multiplicative uncertainty form as

$$
A_{i j}=A_{i j}^{0}\left(1+K_{V}^{i j} \Delta V\right)
$$

where $A_{i j}^{O}$ is the $i, j$ element of the 80 Knot model A matrix, $\Delta V=V_{T}-80$, with units in Knots, and $K_{V}^{i j}$ were chosen to be the average of the change in the $A(i, j)$ element from the $80 \mathrm{Knot}$ to $60 \mathrm{Knot}$ and $100 \mathrm{Knot}$ models. With such an uncertainty model, the perturbation $\Delta(\mathrm{s})$ for robustness analysis is of the form $\Delta(\mathrm{s})=\Delta \mathrm{V}$. I where I is an identity matrix of dimension 13 , and the structured singular value stability robustness measure $\mu$ is given by [18]

$$
\mu=\max _{\omega}[\rho(\mathbf{M}(\mathrm{j} \omega)]
$$

where $\rho[A]$ is the spectral radius of matrix A (maximum absolute eigenvalue of $A$ ) and $M(s)$ is the interconnection matrix for robustness analysis which represents the nominal closed-loop system taking into account the structure of $\Delta(\mathrm{s})$. A detailed discussion of creating the interconnection matrix for this particular study is beyond the scope of this paper. The reader is referred to Ref. [17] for a theoretical discussion of the subject of robustness analysis for structured uncertainties and to Ref. [4] for a detailed exposition on creating the interconnection matrix for various forms of uncertainty models. The structured singular value for A matrix uncertainty as modelled by Eq.(5) is shown in Fig. 
8. Also shown in Fig. 8 is the corresponding result with the control design of Ref. [5]. From Fig. $8, \mu=.02$ for the current control design which implies that for the A matrix uncertainties as modelled, the closed-loop system will remain stable for velocity perturbations of up to $\Delta \mathrm{V}=\frac{1}{\mu}=50$ Knots. For the design of Ref. [5], $\mu=0.065$ which implies that the closed loop system with that control design would have been guaranteed only for velocity perturbations up to $15 \mathrm{Knots}$. In fact, for $\Delta V=15 \mathrm{Knots}$ as modelled, the open-loop A matrix is such that the dutch roll mode is just unstable and the control design of Ref. [5] was found to be unstable for this perturbation. The closed-loop system with the current control design was stable for the full off-design 60 Knot and 100 Knot plant models thus indicating that the use of internal noise model in the $\mathrm{H}_{\infty}$ problem formulation was successful in building-in robustness to variations in the lateral/directional dynamics.

Since the design plant is an integrated flight propulsion system, robustness of the design closed-loop system to changes in the propulsion system dynamics is also an important criterion to be met. As mentioned in Ref. [19], the engine acceleration (fan/compressor speed changes) response to fuel flow characteristics can vary over a wide range due to the cumulative effect of various variables such as wear and differences in manufacturing tolerances, variable geometry setting, inlet distortion, environmental conditions etc. For the purposes of robustness analysis, this variation in propulsion dynamics can be represented as uncertainty in the A matrix and $\mathrm{B}$ matrix elements corresponding to the change in rotor speed rates $(\stackrel{\mathrm{N}}{2}, \mathrm{~N} 25)$ with change in rotor speeds and fuel flow respectively, i.e. $A(i, j)$ and $B(i, k)$ with $i$ and $j=9,10$ and $k=7$ in the design model of Eq. (1). Structured singular value robustness with the $80 \mathrm{Knot}$ design model and the current controller design was performed considering independent multiplicative perturbations in these 6 elements of the $A$ and $B$ matrices. This analysis gave $\mu=1.276$ which implies a stability margin $S M=\frac{1}{\mu}=0.79$, i.e. the closed-loop system will remain stable for changes of up to $79 \%$ from the $80 \mathrm{Knot}$ model in these A and B matrix elements. Thus the control design provides robustness to large variations in the engine dynamic 
response characteristics. The actual change in these elements between the design model and the off-design $60 \mathrm{Knot}$ and $100 \mathrm{Knot}$ models was much less than $79 \%$ thus indicating that the design controller will provide robustness to changes in engine dynamics due to changes in the engine operating point within the transition envelope.

\section{Controller Scheduling}

The general approach to controller scheduling is to design linear controllers at various operating points and then perform some kind of curve fit to the various controller gains with the critical operating point conditions as the independent parameters. For a controller of order $n$ with $m$ inputs and $r$ outputs, there will be $n(1+m+r)+m r$ controller parameters to schedule with the controller represented in a minimal parameter state-space form [20]. For the current control design, $n=14, m=18$ ( $\bar{y}$ of Eq. (4), 6 tracking errors and WB3) and $r=12$ resulting in 434 parameters to be scheduled. Even with further controller simplification such as removing the insignificant feedback paths, and partitioning the controller into separate airframe and propulsion sub-system controllers [1] with further partitioning of the airframe controller into longitudinal and lateral subcontrollers, the number of parameters to be scheduled may still be quite large. Moreover, the whole procedure of designing simplified controllers for the different operating points will be quite cumbersome and time consuming. A simpler controller scheduling scheme that exploits the robustness properties of the nominal controller is discussed in the following.

The fundamental objective in using modern robust multivariable control design techniques is to reduce the controller complexity while guaranteeing the desired performance and stability robustness characteristics. A robust $H_{\infty}$ control design problem was formulated in this paper. The stability robustness of the resulting control design was demonstrated with special attention being given to variations in the elements of the system A matrix with changes in the operating point - trim airspeed for the model variations being considered. For a control design which is robust for changes in the plant A matrix, controller scheduling should only be needed to account for changes in the plant B matrix, 
i.e. changes in control effectiveness. For example, for the aircraft models being considered, the effectiveness of the aerodynamic control surfaces decreases with airspeed. Therefore the control of the aircraft attitude angles and angular rates is transferred from aerodynamic surfaces to propulsion system generated moments via RCS and nozzle vectoring controls as the aircraft slows down. The desired control redistribution can be achieved by control scheduling of the form

$$
\mathrm{K}(\mathrm{s})=\mathrm{K}_{\mathrm{s}} \mathrm{K}^{\mathrm{O}}(\mathrm{s})
$$

where $\mathrm{K}(\mathrm{s})$ is the scheduled controller, $\mathrm{K}_{\mathrm{s}}$ is the control redistribution matrix and $\mathrm{K}^{\circ}(\mathrm{s})$ is the controller designed for the nominal design point. Note that such a controller scheduling will remove the burden of having to do a nominal control design at too many operating points and also the number of parameters to be scheduled will be lower. For a controller with $m$ outputs, the number of parameters to be scheduled will be at most $\mathrm{m}^{2}$ which corresponds to 144 parameters for the current control design. However, the number of these parameters can be drastically reduced by taking into account the separation of the control effectors into different control axes.

A procedure for developing controller scheduling of the form of Eq. (8) is discussed in the following and evaluation results are presented for the current design example. This controller scheduling approach was motivated by the control selector design approach of Ref. [21] wherein a decentralized, hierarchical approach to integrated flight propulsion control design was developed.

The controller scheduling concept is demonstrated in Fig. 9 which shows the nominal (design point) control loop and the control loop at an off-design operating point. The plant feedthrough matrix $D$ is not shown in Fig. 9 for simplicity of discussion. If the design controller is robust to changes in the A matrix and the controlled and feedback outputs, $\bar{z}$ and $\bar{y}$ respectively, are the same for off-design models, then choosing $K_{S}$ such that

$$
\mathrm{BK}_{\mathrm{S}} \approx \mathrm{B}^{\mathrm{O}}
$$


will ensure that the loop at point (i) in Fig. 9 is invariant to changes in B matrix thus guaranteeing robustness to changes in control effectiveness. One can then solve for an approximate value of $\mathrm{K}_{\mathrm{S}}$ by using pseudo-inverse techniques [22] on Eq. (9). In order to perform the pseudo-inverse, it is important to ensure that the control effectiveness matrix B used in Eq. (9) is full rank, i.e. it represents the minimum number of independent controls for the problem being considered. For the integrated flight propulsion model of (1) to (3) the control degrees of freedom are the generation of the forces and moments for aircraft translational and rotational motion along the three axes $(\dot{u}, \dot{v}, \dot{w}, \dot{p}, \dot{q}, \dot{\mathrm{r}})$, and the engine fan acceleration (N2). The controller scheduling gains are then given by

$$
\mathrm{K}_{\mathrm{S}}=\dot{\mathrm{N}}(\overline{\mathrm{BN}})^{\#} \overline{\mathrm{B}}^{\mathrm{O}}
$$

where $\bar{B}$ consists of the first six and the 9th row of $B$ of Eq. (1) with all the columns, \# represents pseudo-inverse, and $N=\operatorname{diag}\left(\bar{u}_{\max }\right)$ with $\bar{u}_{\max }$ corresponding to the maximum allowable control deflections.

For the current design the controller scheduling gains $\mathrm{K}_{\mathrm{S}}$ were obtained for the off-design $60 \mathrm{Knot}$ and $100 \mathrm{Knot}$ models using the appropriate $\bar{B}$ matrices. Fig. 10 shows a comparison of the closed-loop system response to lateral $(\mathrm{Pv})$ command for the three flight conditions with the scheduled controller. Note that the controller scheduling maintains roll tracking performance with automatic turn coordination demonstrated by the low sideslip response. This controller scheduling provided robust decoupled command tracking for all the controlled variables in $\bar{z}$ of Eq. (5) except for the pitch rate variable Qv. For the case of Qv command, although the tracking performance with the scheduled controller was much improved over that without any controller scheduling, there was a large degradation in performance at the off-design conditions when compared to the nominal performance. To understand the reasons for this degradation in pitch tracking performance, further evaluations were performed for the Qv command case. First the closed-loop system was evaluated with the nominal controller keeping the plant B matrix constant at the nominal design condition and changing the A matrix to the off-design conditions. Then the 
closed-loop system was evaluated with the scheduled controller keeping the A matrix constant at the nominal design condition and changing the $\mathrm{B}$ matrix to the off-design conditions. Robust tracking performance was obtained for the latter case but not for the former case. This result indicates that the controller scheduling scheme does provide robustness to changes in control effectiveness, however the nominal control design itself is not robust in pitch tracking performance to changes in the A matrix. This lack of performance robustness is due to the fact that aircraft pitch dynamics are a strong function of airspeed. Note that the results presented in the previous section had mainly demonstrated stability robustness and not performance robustness to changes in the $\mathrm{A}$ matrix. Clearly then guaranteeing performance robustness to changes in the A matrix is very critical to making the suggested controller scheduling scheme work. Although performance robustness analysis can be performed using structured singular value concepts, reliable numerical algorithms to do such analysis are not currently available. Since the internal noise model procedure was successful in building-in performance robustness in the lateral-directional axes, the possibility of using a similar approach for the pitch axis will be investigated in future design studies.

\section{Conclusions}

The Integrated Flight/Propulsion Control system design presented in this paper demonstrates the applicability of an $\mathrm{H}_{\omega}$ control synthesis technique to integrated control design for complex systems such as Short Take-Off and Vertical Landing (STOVL) aircraft. The capability to address closed-loop performance, robustness and control actuation trade-offs within the framework of an $\mathrm{H}_{\omega}$ control problem formulation was demonstrated. In particular, the $H_{w}$ control design for the IFPC problem, as formulated herein, provided robustness to the absolute nonlinearity associated with the compressor bleed flow demand from the Reaction Control System and to changes in the plant system dynamics over the transition flight envelope. A controller scheduling approach which has the potential to considerably reduce the complexity of control implementation over the 
flight envelope and which exploits the robustness properties of the linear point design $H_{\omega}$ based controller was developed and demonstrated.

\section{Acknowledgement}

The authors would like to thank Dr. Duane Mattern and Ms. Michelle Bright for their assistance in generating the linear airframe and propulsion models used in this study. 


\section{References}

[1] Garg, S., Ouzts, P.J., and Lorenzo, C.F., "IMPAC - an Integrated Methodology for Propulsion and Airframe Control," 1991 American Control Conference, Boston, MA, June 1991.

[2] Doyle, J.C., Glover, K., Khargonekar, P.P., and Francis B.A., "State-Space Solutions to Standard $\mathrm{H}_{2}$ and $\mathrm{H}_{\infty}$ Control Problems, "IEEE Transactions on Automatic Control, Vol. 34, No. 8, August 1989, pp. 831-847.

[3] Safonov, M.G., Limebeer, D.J.N., and Chiang, R.Y., "Simplifying the $H_{w}$ Theory via Loop-Shifting, Matrix-Pencil and Descriptor Concepts," Int. J. of Control, 1989, Vol. 50, No. 6, pp. 2467-2488.

[4] "MATRIXx Robust Control Module - User's Guide," Integrated Systems Inc., Santa Clara, CA, October 1989.

[5] Garg, S., Mattern, D.L., Bright, M.M., and Ouzts, P.J., "H-Infinity Based Integrated Flight/Propulsion Control Design for a STOVL Aircraft in Transition Flight," AIAA Paper 90-3335, Guidance, Navigation and Control Conference, Portland, OR, August 1990.

[6] Akhter, M.M., Vincent, J.H., Berg, D.F., and Bodden, D.S., "Simulation Development for US/Canada Controls Technology Program," Proceedings of the Twentieth Annual Modeling and Simulation Conference, University of Pittsburgh, Pittsburgh, PA, June 1989.

[7] McRuer, D.T., Ashkenas, I., and Graham, D., "Aircraft Flight Dynamics and Automatic Control," Princeton University Press, 1973.

[8] Safonov, M.G, and Chiang, R.Y., "CACSD Using the State-Space $\mathrm{L}_{\infty}$ Theory - A Design Example," IEEE Trans. on Automatic Control, AC-33, No. 5, pp. 477-479, May 1988.

[9] Chiang, R.Y., Safonov, M.G., and Tekawy, J.A., "H Flight Control Design with Large Parametric Robustness," Proceedings of the 1990 American Control Conference, San Diego, CA, May 1990.

[10] "Military Specification - Flying Qualities of Piloted V/STOL Aircraft," Mil-F-83300, Wright Patterson AFB, OH, December 1970.

[11] Hoh, R.H., and Mitchell, D.G., "Proposed Revisions to MIL-F-83300 V/STOL Flying Qualities Specification," NADC-82146-60, Naval Air Development Center, Warminster, PA, January 1986.

[12] Ogata, K., "Modern Control Engineering," Prentice Hall Inc., 1970.

[13] Reichert, R., "Application of H-Infinity Control to Missile Autopilot Design," AIAA Paper 89-3550, Proceedings of the AIAA Guidance, Navigation and Control Conference, Boston, MA, August 1989, pp. 1065-1072. 
[14] Kokotovic, P.V., and Sannvie, P., "Singular Perturbation Method for Reducing Model Error in Optimal Control Design, "IEEE Trans. on Automatic Control, AC-13, pp.377-384, 1968.

[15] Moore, B.C., "Principal Component Analysis in Linear Systems: Controllability, Observability and Model Reduction," IEEE Trans. on Automatic Control, Vol. AC-26, Feb. 1981, pp. 17-31.

[16] Enns, D.F., "Model Reduction for Control System Design," Ph.D. Dissertation, Dept. of Aeronautics and Astronautics, Stanford Univ., Stanford, CA, June 1984.

[17] Doyle, J.C., "Structured Uncertainty in Control System Design," Proceedings of the 24th Conference on Decision and Control, Ft. Lauderdale, FL, Dec. 1985, pp. 260-265.

[18] Apkarian, P.R., "Structured Stability Robustness Improvement by Eigenspace Assignment Techniques: A Hybrid Methodology," Journal of Guidance, Control and Dynamics, Vol. 12, No. 2, March-April 1989, pp. 162-168.

[19] Sobey, A.J., and Suggs, A.M., "Control of Aircraft and Missile Powerplants," John Wiley and Sons Inc., 1963.

[20] Ly, U.L., Bryson, A.E., and Cannon, R.H., "Design of Low-Order Compensators using Parameter Optimization," Automatica, Vol. 21, No. 3, pp. 315-318, 1985.

[21] Shaw, P.D., Rock, S.M., and Fisk, W.S., "Design Methods for Integrated Control Systems," AFWAL-TR-88-2061, Wright Patterson AFB, OH, June 1988.

[22] Noble, B., and Daniel, J.W., "Applied Linear Algebra," Prentice-Hall Inc., 1977. 
Table 1. Trim Control for Linear Models

\begin{tabular}{|c|c|c|c|}
\hline \multicolumn{4}{|c|}{ (Listed as percent (\%) of 80 Knot Model trim values) } \\
\hline $\mathrm{V}_{0}$ (Knots) & 60 & 80 & 100 \\
\hline $\mathrm{A} 8_{0}(\%)$ & 11 & 100 & 268 \\
\hline $\operatorname{ETA}_{0}(\%)$ & 96 & 100 & 118 \\
\hline $\mathrm{A} 78_{0}(\%)$ & 133 & 100 & 32 \\
\hline $\mathrm{WF}_{\mathrm{o}}(\%)$ & 116 & 100 & 71 \\
\hline $\mathrm{N} 2{ }_{\mathrm{o}}(\%)$ & 104 & 100 & 90 \\
\hline
\end{tabular}

2. Eigenvalues of Linear Models

\begin{tabular}{|c|c|c|c|}
\hline & Eigenvalue & & Description \\
\hline 60 & 80 & 100 & $\mathrm{~V}_{\mathrm{o}}$ (Knots) \\
\hline $\begin{array}{c}-7.9 \mathrm{e}-02 \\
-0.09 \pm j 0.24 \\
1.05 \\
-1.64 \\
-1.74 \\
0.05 \pm j 1.99 \\
-5.58 \pm \mathrm{j} 0.74\end{array}$ & $\begin{array}{c}-8.5 \mathrm{e}-02 \\
-0.11 \pm \mathrm{j} 0.28 \\
1.29 \\
-1.73 \\
-2.09 \\
-0.23 \pm \mathrm{j} 2.27 \\
-4.12 \\
-7.11\end{array}$ & $\begin{array}{c}-7.9 \mathrm{e}-02 \\
-0.12 \pm \mathrm{j} 0.31 \\
1.44 \\
-1.77 \\
-2.45 \\
-0.48 \pm \mathrm{j} 2.53 \\
-3.33 \\
-3.83\end{array}$ & $\begin{array}{c}\text { Spiral Mode } \\
\text { Phugoid Mode } \\
\text { Unstable SPa } \\
\text { Roll Mode } \\
\text { Stable SP } \\
\text { Dutch Roll } \\
\text { Rotor Speeds }\end{array}$ \\
\hline $\begin{array}{l}-29.73 \\
-38.67 \\
-172.0\end{array}$ & $\begin{array}{l}-29.39 \\
-38.21 \\
-199.7\end{array}$ & $\begin{array}{l}-27.73 \\
-39.95 \\
-277.1\end{array}$ & $\begin{array}{l}\text { Temperatures } \\
\text { Pressure Mode }\end{array}$ \\
\hline
\end{tabular}

aShort Period 


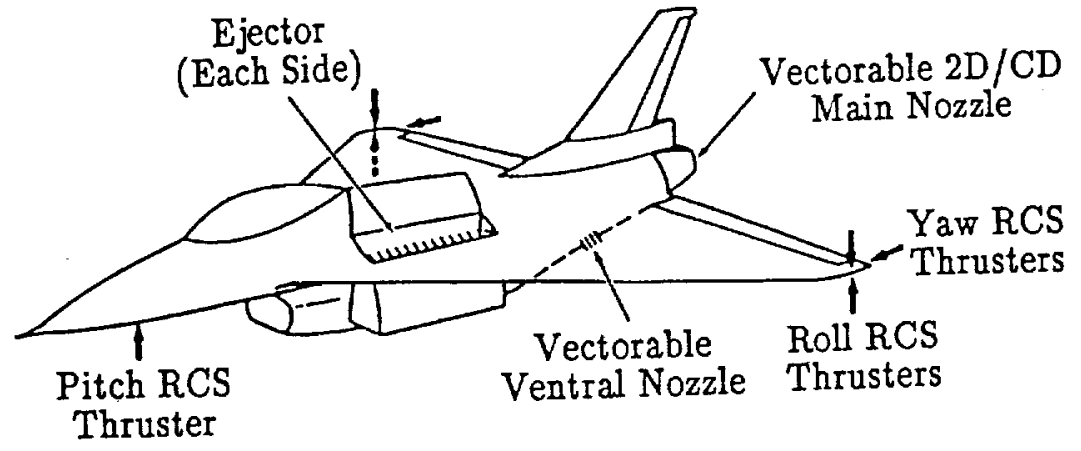

Fig. 1 Control Effectors for E-7D Aircraft

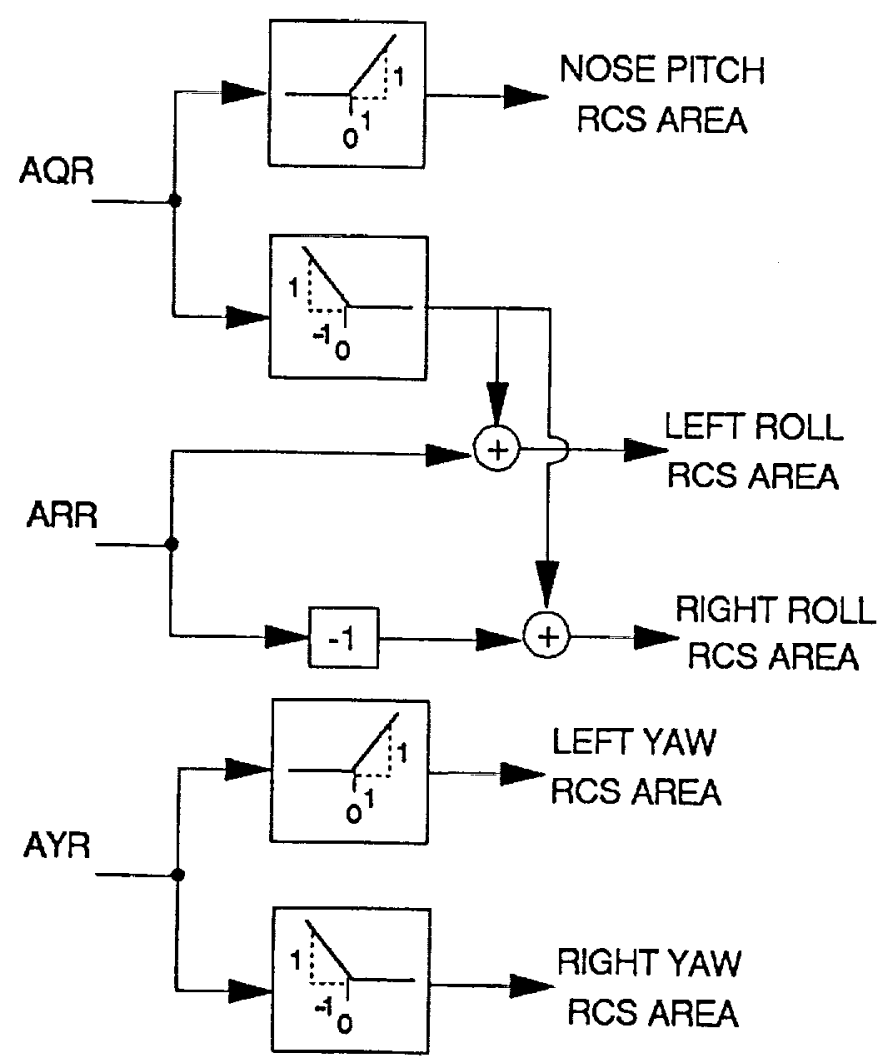

Fig. 2 RCS Area Distribution Logic for Control Implementation 


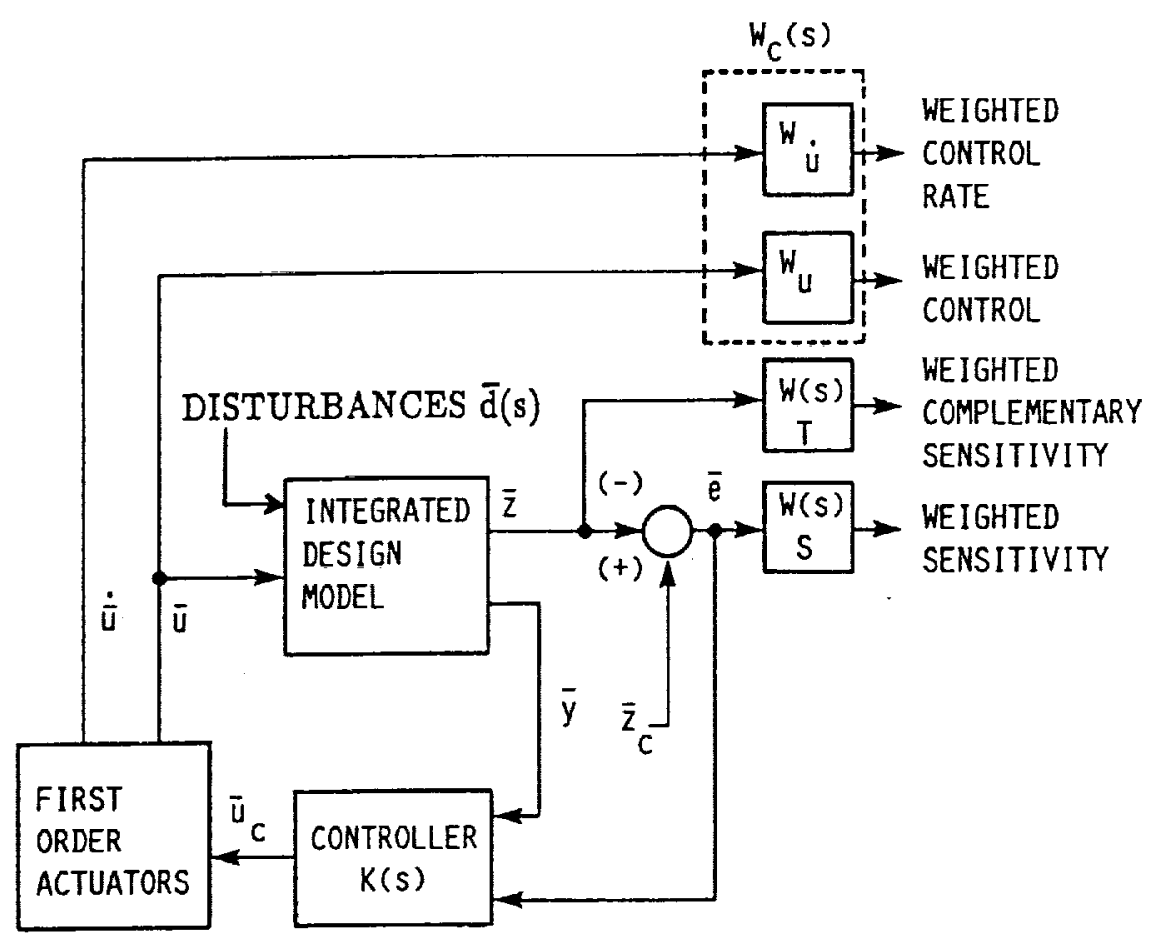

Fig. 3 Block Diagram for $\mathrm{H}_{\mathrm{w}}$ Formulation of IFPC Feedback Design

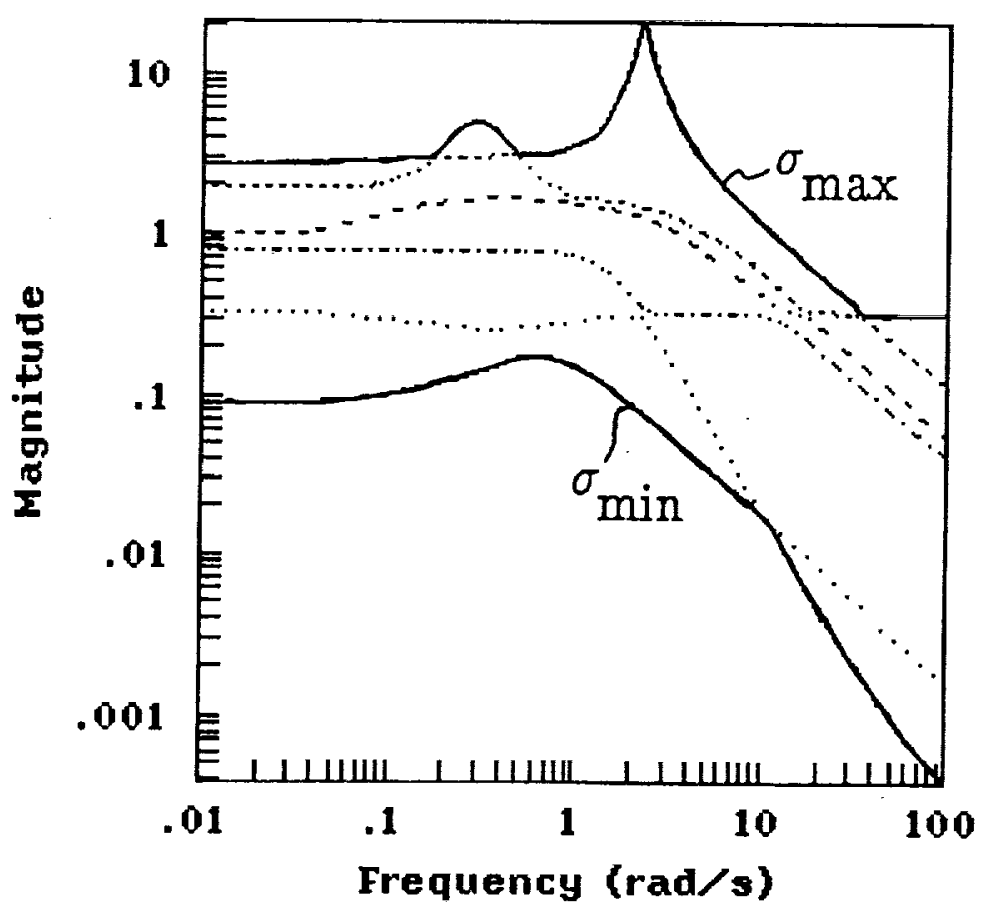

Fig. 4 Singular Values of Scaled Design Plant 


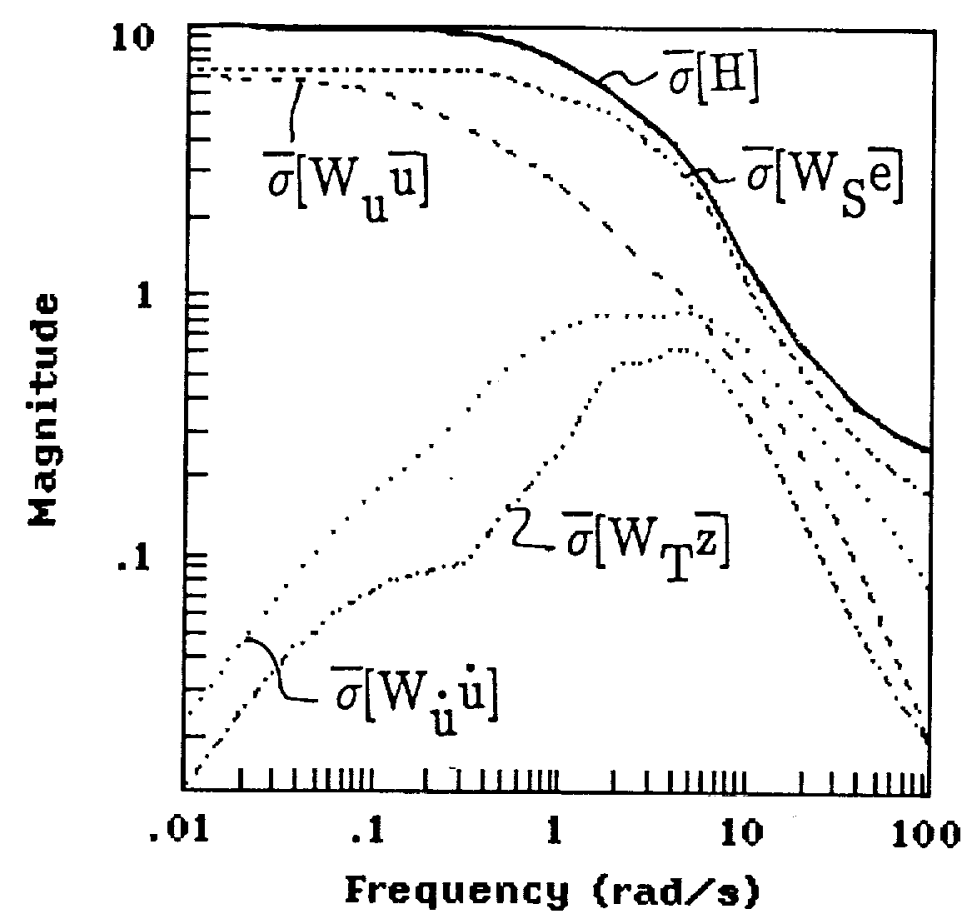

Fig. 5 Closed-Loop Weighted Norms for $\mathrm{H}_{\infty}$ Controller

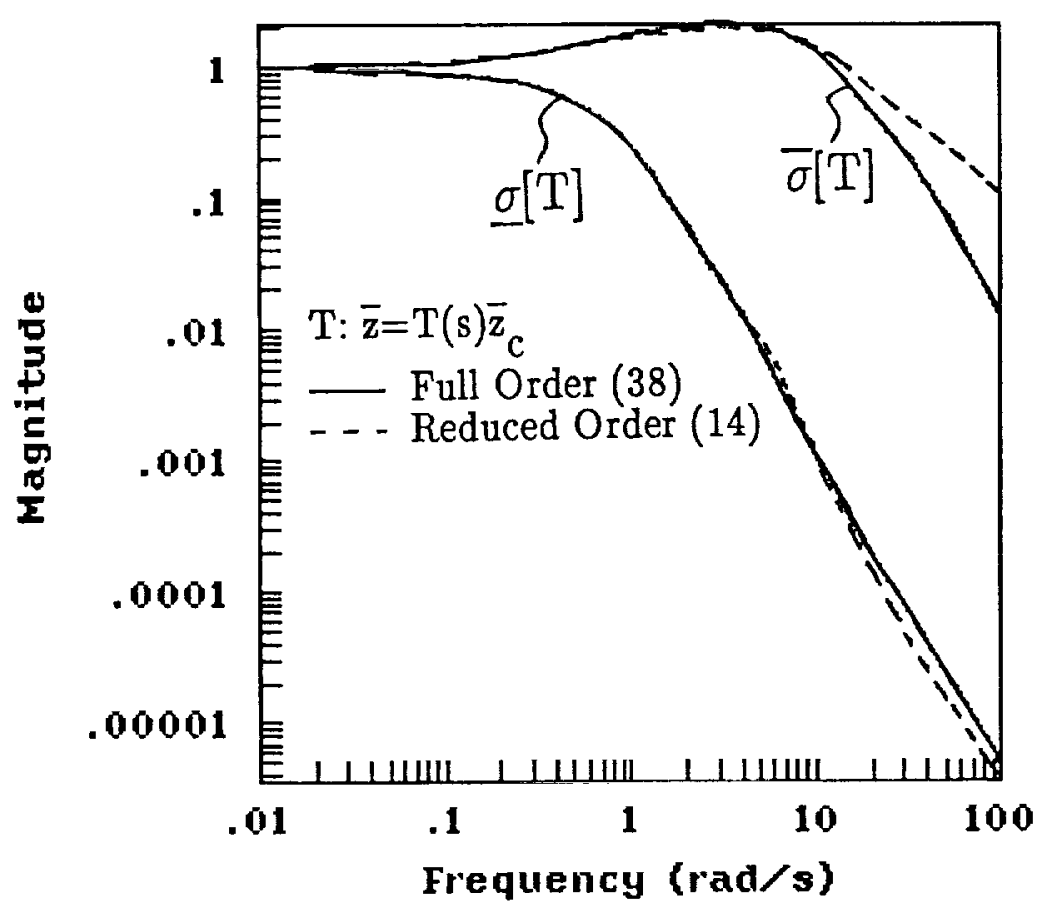

Fig. 6 Closed-Loop Tracking Singular Values with Full and Reduced-Order Controllers 

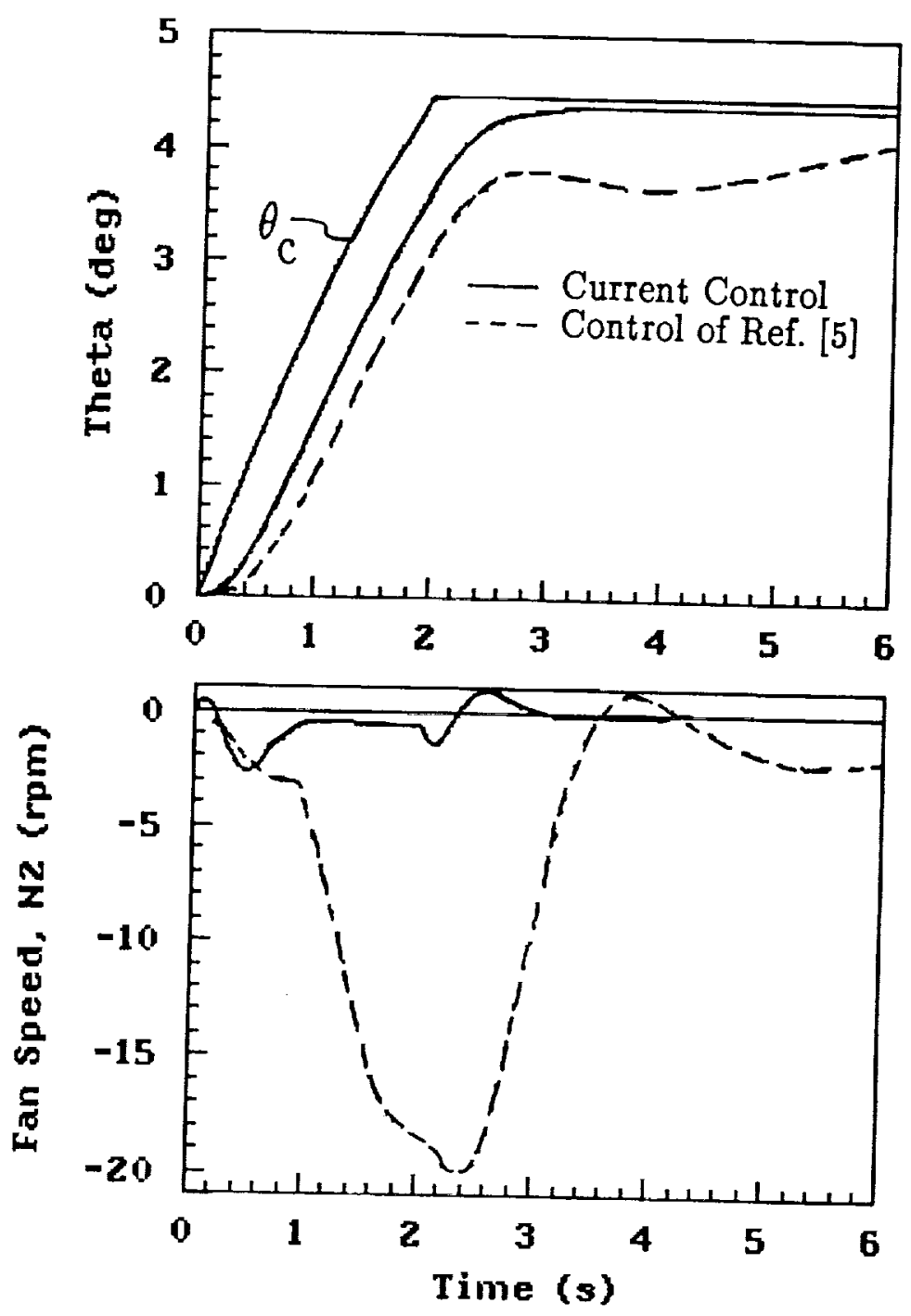

Fig. 7 Pitch Tracking Performance in the presence of Bleed Flow Nonlinearity 


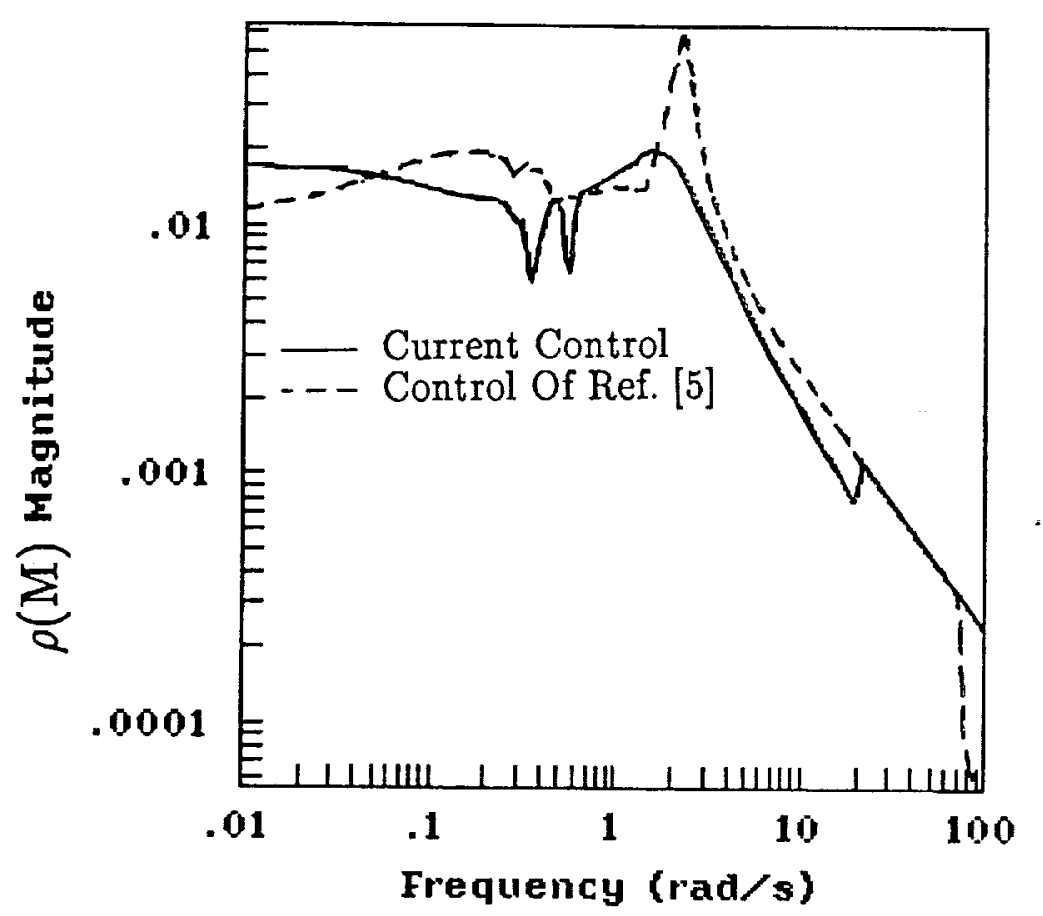

Fig. 8 Stability Robustness Measure $\rho(M)$ for Variations in Airframe portion of Plant A Matrix

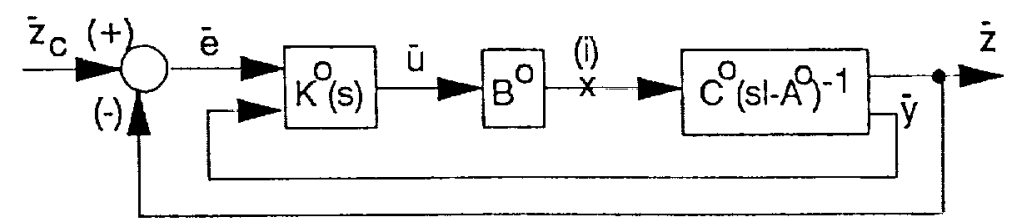

(a) Nominal Control Loop

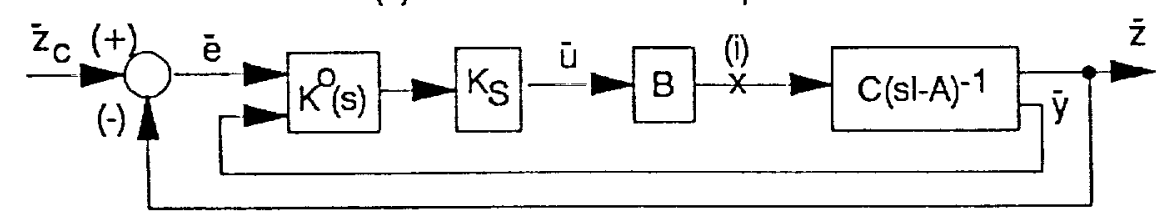

(b) Off-Design Control Loop

Fig. 9 Controller Scheduling for Variation in Control Effectiveness 

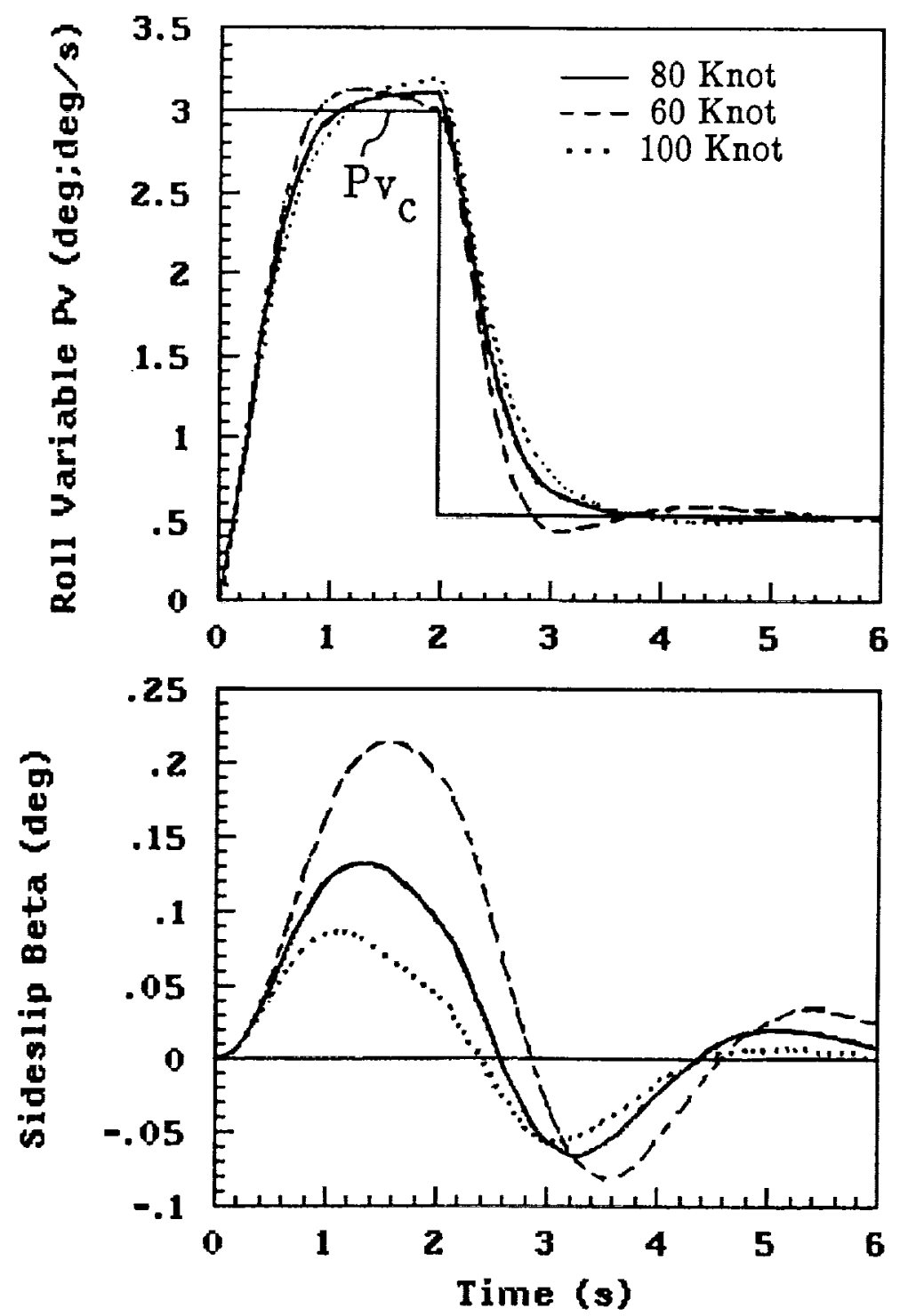

Fig. 10 Roll Variable (Pv) Tracking and Sideslip Response at the three operating points with Scheduled Controller 



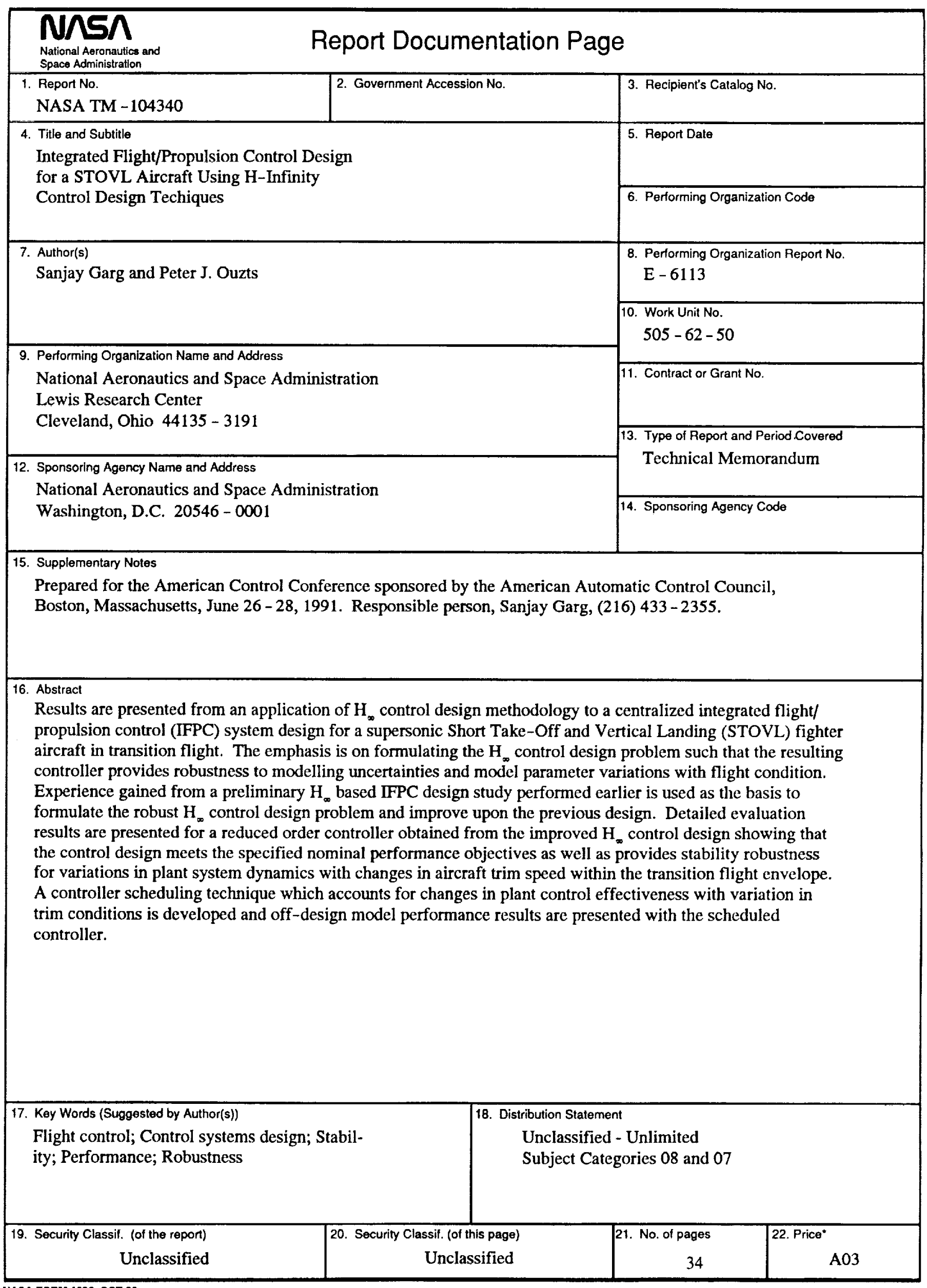

